\title{
EFFECTS OF POLYMYXIN-B ON TNF- $\alpha$ PRODUCTION IN EQUINE WHOLE BLOOD STIMULATED WITH THREE DIFFERENT BACTERIAL TOXINS
}

Running title: Polymyxin-B against three bacterial toxins

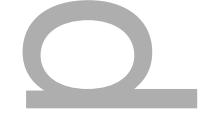

Jennifer R. Bauquier ${ }^{1}$, Brett S. Tennent-Brown ${ }^{1}$, Elizabeth Tudor ${ }^{2}$, Simon R. Bailey ${ }^{2}$

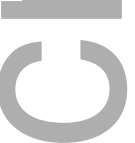

1. Department of Veterinary Clinical Sciences, Melbourne Veterinary School, Faculty of

Veterinary and Agricultural Sciences, University of Melbourne

2. Department of Veterinary Biosciences, Melbourne Veterinary School, Faculty of

Veterinary and Agricultural Sciences, University of Melbourne

Address correspondence to:

Jennifer R. Bauquier

Faculty of Veterinary and Agricultural Sciences

University of Melbourne

250 Princes Hwy

Werribee

Victoria, 3030

Australia

Ph: +61397312268

Email: jbauquier@unimelb.edu.au

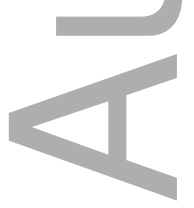

This is the author manuscript accepted for publication and has undergone full peer review but has not been through the copyediting, typesetting, pagination and proofreading process, which may lead to differences between this version and the Version of Record. Please cite this article as doi: 10.1111/jvp.12445

This article is protected by copyright. All rights reserved 


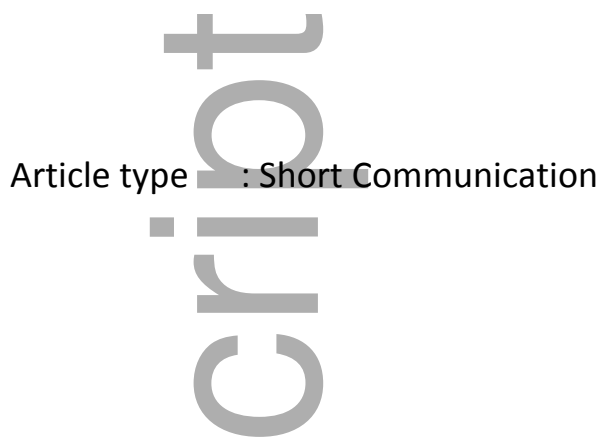

\section{Abstract}

Polymyxin-B is used to treat equine systemic inflammation. Bacterial toxins other than lipopolysaccharide (LPS) contribute to systemic inflammation but the effects of polymyxin-B on these are poorly defined. Whole blood aliquots from 6 healthy horses diluted 1:1 with RPMI were incubated for 21 hours with $1 \mu \mathrm{g} / \mathrm{ml}$ of LPS, lipoteichoic acid (LTA) or peptidoglycan (PGN) in the presence of increasing concentrations of polymyxin-B (10-3000 $\mu \mathrm{g} / \mathrm{ml}$ ). A murine L929 fibroblast bioassay was used to measure TNF- $\alpha$ activity. PolymyxinB significantly inhibited the effects of all three bacterial toxins. Analysis of variance showed the $\mathrm{IC}_{50}$ value for polymyxin-B for TNF- $\alpha$ inhibition caused by LTA $(11.19 \pm 2.89 \mu \mathrm{g} / \mathrm{ml}$ polymyxin-B) was significantly lower $(\mathrm{P}=0.009)$ than the values for LPS $(46.48 \pm 9.93$ $\mu \mathrm{g} / \mathrm{ml})$ and PGN (54.44 $\pm 8.97 \mu \mathrm{g} / \mathrm{ml})$. There was no significant difference in $\mathrm{IC}_{50}$ values between LPS and PGN (P>0.05). Maximum inhibition of TNF- $\alpha$ was $77.4 \%, 73.0 \%$, and $82.7 \%$ for LPS, PGN and LTA respectively and was not significantly different between toxins. At the two highest concentrations of polymyxin-B, TNF- $\alpha$ began to increase. These data suggest that Polymyxin-B may inhibit the effects of bacterial toxins other than LPS and might be a more potent inhibitor of LTA than LPS or PGN. 
The systemic inflammatory response syndrome (SIRS) is a common complication of gastrointestinal disease and severe infection in horses, with consequences such as coagulopathies, multiple organ dysfunction, laminitis and death (Lewis, Chan, Pinheiro, Armitage-Chan, \& Garden, 2012; Moore \& Vandenplas, 2014; Werners, Bull, \& FinkGremmels, 2005). Lipopolysaccharide (LPS) from Gram negative bacteria has been most widely investigated in equine SIRS (Burrows, 1971, 1979; Duncan, Meyers, Reed, \& Grant, 1985; Fessler et al., 1989; Forbes, Church, Savage, \& Bailey, 2012; Peek et al., 2004; Peiró et al., 2010; Tadros \& Frank, 2012); however, toxins such as lipoteichoic acid (LTA) from Gram positive bacteria or peptidoglycan (PGN) found in both Gram positive and negative bacteria have substantial inflammatory effects and contribute to SIRS in horses and other species (Declue, Johnson, Day, Amorim, \& Honaker, 2012; Johns et al., 2009; Leise, Yin, Pettigrew, \& Belknap, 2010; Russell, Axon, Blishen, \& Begg, 2008; Schwandner, Dziarski, Wesche, Rothe, \& Kirschning, 1999; Theelen, Wilson, Edman, Magdesian, \& Kass, 2014; Wang et al., 2003). Lipopolysaccharide elicits inflammation through a complex series of steps including activation of toll-like receptor-4 (TLR-4) (Werners et al., 2005). Lipoteichoic acid and PGN also elicit inflammatory cascades but largely through activation of toll-like receptor-2 (TLR-2) (Schwandner et al., 1999). Severe Gram positive infections are increasingly recognised in neonatal foal sepsis (Theelen et al., 2014). Therefore further investigation into treatment of Gram positive sepsis and SIRS is warranted.

Polymyxin-B is a cationic peptide antibiotic that binds to the lipid A moiety of LPS and thus prevents the binding of LPS to lipopolysaccharide-binding protein (LBP) (Morrison \& Jacobs, 1976). It is commonly administered to horses with SIRS to help reduce the effects of inflammation induced by LPS. While the effect of polymyxin-B against LPS-induced inflammation in horses is well documented in in vivo and ex vivo experimental models (Barton, Parviainen, \& Norton, 2004; Morresey \& Mackay, 2006; Parviainen, Barton, \& Norton, 2001), its anti-inflammatory effects against other bacterial toxins in horses are not well described.

The aim of this study was to determine the efficacy of polymyxin-B in reducing TNF- $\alpha$ production in response to stimulation by three different bacterial toxins (LPS, LTA and PGN) in an in vitro equine whole blood model. 
Six mature healthy Standardbred horses were used for the study. Each horse had whole blood drawn from either jugular vein and collected into sodium citrate tubes (Vacutainer). Whole blood was diluted 1:1 with RPMI cell culture medium, and then pipetted into multiple aliquots of $500 \mu \mathrm{L}$ in sterile $1.5 \mathrm{ml}$ pyrogen- and DNA-free Eppendorf tubes. Except for negative and positive controls, samples were then treated with increasing concentrations of polymyxin-B (Bova compounding, Sydney, Australia). Ten minutes after addition of polymyxin-B, all samples (except the negative control) were stimulated by the addition of LPS (E. coli O55:B5), LTA (Enterococcus hirae) or PGN (Staphylococcus aureus), achieving a final toxin concentration of $1 \mu \mathrm{g} / \mathrm{ml}$. This toxin concentration was used to ensure a reliably measureable TNF- $\alpha$ response based on preliminary (unpublished) studies performed to identify optimal toxin concentrations for the assays used in our laboratory and previous studies performed in our laboratory (Bauquier, Tudor, \& Bailey, 2015). For each toxin for each horse, two samples comprised negative (no toxin and no polymyxin-B) and positive $(1 \mu \mathrm{g} / \mathrm{ml}$ of toxin but no polymyxin-B) controls. Remaining samples contained 1 $\mu \mathrm{g} / \mathrm{ml}$ toxin and polymyxin-B at the following concentrations: 10, 30, 100, 300, 1000 and $3000 \mu \mathrm{g} / \mathrm{mL}$. All samples were incubated at $37^{\circ} \mathrm{C}$ with continual mixing for 21 hours.

Samples were then centrifuged at $2000 \mathrm{~g}$ for 5 minutes, the supernatant removed and stored at $-20^{\circ} \mathrm{C}$ for 8 weeks until TNF- $\alpha$ assays were performed.

Tumour neerosis factor- $\alpha$ was measured using a murine L929 fibroblast bioassay (Cudmore, Muurlink, Whittem, \& Bailey, 2013; Hay \& Cohen, 1989). L929 cells (ECACC cell lines; purchased through Sigma-Aldrich Pty. Ltd., Sydney, Australia) were cultured in DMEM medium, containing $10 \%$ fetal calf serum, 100 units $/ \mathrm{ml}$ penicillin and $0.1 \mathrm{mg} / \mathrm{ml}$ streptomycin, at $37^{\circ} \mathrm{C}$ in $5 \% \mathrm{CO}_{2}$. Recombinant equine TNF- $\alpha$ (Thermo Scientific Inc., Rockford IL USA; 78 to 5000 pg/ml), was used to create standard curves. Duplicate samples were pipetted into a 96-well plate. Actinomycin-D at $20 \mu \mathrm{g} / \mathrm{mL}$ was then added to sensitize bioassay cells to TNF- $\alpha$-dependent killing. Plates were incubated at $37^{\circ} \mathrm{C}$ in $5 \% \mathrm{CO}_{2}$ for 24 hours. The assay was then developed by the addition of tetrazole dye, 3-(4,5-dimethylthiazol2-yl)-2,5-diphenyltetrazolium bromide (MTT reagent) and incubated as above for 8 hours, followed by the addition of $100 \mu$ l detergent reagent to each well and incubated as above for 4 hours. Plates were read at an absorbance of $560 \mathrm{~nm}$ with a reference wavelength of $690 \mathrm{~nm}$ (Synergy H1 Hybrid Microplate Reader, BioTek, Vermont, USA). TNF- $\alpha$ concentrations were determined from the standard curve on each plate, using Gen5 Microplate Reader Software (BioTek, Vermont, USA). 
For measured TNF- $\alpha$ concentrations, nonlinear regression (dose-response curve fitting) was used to determine the $\mathrm{IC}_{50}$ for polymyxin-B against each toxin. A one-way ANOVA with Tukey's multiple comparisons was then used to determine differences in $\mathrm{IC}_{50}$ and maximum inhibition of polymyxin-B between toxins. Significance was set at $\mathrm{P}<0.05$.

Polymyxin-B inhibited TNF- $\alpha$ production stimulated by all bacterial toxins (Figure 1). Analysis of variance showed the $\mathrm{IC}_{50}$ value for inhibition of TNF- $\alpha$ production caused by LTA $(11.19 \pm 2.89 \mu \mathrm{g} / \mathrm{ml}$ polymyxin $)$ was significantly lower $(\mathrm{P}=0.009)$ than the values for LPS $(46.48 \pm 9.93 \mu \mathrm{g} / \mathrm{ml})$ and PGN $(54.44 \pm 8.97 \mu \mathrm{g} / \mathrm{ml})$. There was no significant difference between LPS and PGN ( $>>0.05)$. Maximum inhibition by polymyxin-B was $77.4 \%$ for LPS, $73.0 \%$ for PGN, and $82.7 \%$ for LTA. There was no significant difference in maximum inhibition between any toxins. At the higher concentrations of polymyxin-B (1000-3000 $\mu \mathrm{g} / \mathrm{ml}$ ), TNF- $\alpha$ concentrations increased again (Figure 2).

Our results showed that polymyxin-B appeared to be a more potent inhibitor of TNF- $\alpha$ production for LTA than either LPS or PGN. This was somewhat unexpected, as the structure of polymyxin-B suggests it should bind best to the lipid A portion of LPS and thus inhibit this toxin most potently. Inhibition of LTA-induced production of TNF- $\alpha$ by polymyxin-B at 10 $\mu \mathrm{g} / \mathrm{ml}$ has been found in another study using human peripheral blood mononuclear cells (PBMCs), where significant TNF- $\alpha$ reduction was seen despite increasing concentrations of LTA (Jaber, Barrett, et al., 1998). This group hypothesised that the cationic amino group binding of polymyxin-B was likely non-specific for lipid A, and it could therefore bind to other appropriate sites on other bacterial toxins (Jaber, Barrett, et al., 1998).

Gram positive bacteria produce five types of LTA; Enterococcus hirae (the bacterial origin of the LTA used in this study) contains LTA types I and II (Percy \& Grundling, 2014). The various LTA types all contain glycolipid anchor sites that are responsible for stimulation of cytokine production (Suda et al., 1995). Polymyxin-B has a narrow antimicrobial spectrum and is primarily active against Gram negative aerobes. Although initial binding to LPS appears to be important in polymyxin-B's activity, the antimicrobial mechanism of action is not completely understood (Bergen et al., 2012). Cationic peptides other than polymyxin-B are able to bind LTA and inhibit cytokine production. The precise mechanism for binding has not been explored (Scott, Gold, \& Hancock, 1999) but the glycolipid anchor sites of LTA could act as binding sites for the cationic peptides (Tsutsui, Kokeguchi, Matsumura, \& Kato, 1991). Since polymyxin-B has limited or no activity against Gram positive bacteria, it is 
possible it can only bind free LTA. Interestingly, other cationic peptides can kill Gram positive bacteria but the antimicrobial action is thought to be unrelated to LTA binding (Scott et al., 1999).

Our results also indicate that polymyxin-B can inhibit inflammatory effects of PGN. The immunogenic portion of PGN is the disaccharide-oligopeptide fraction, with muramyl dipeptide as the minimum adjuvant active structure (Ellouz, Adam, Ciorbaru, \& Lederer, 1974; Kusumoto, Fukase, \& Shiba, 2010). It is therefore plausible that this is the site of polymyxin-B binding on the PGN molecule with subsequent inhibition of pro-inflammatory action. Further investigation is needed to fully elucidate binding sites for polymyxin-B to bacterial toxins other than LPS.

Although a mechanism for polymyxin-B binding to LTA seems the most likely explanation for greater LTA inhibition, there are other possibilities. Contamination of commercial sources of LTA with LPS have been described (Gao, Xue, Zuvanich, Haghi, \& Morrison, 2001). We did not test our commercial LTA for the presence of LPS; however, given the significantly more potent reduction of TNF- $\alpha$ production of LTA compared to LPS, it is unlikely that LPS contamination could explain the entirety of this difference. Similarly, LPS and PGN can also be contaminated with other bacterial toxins (Tsan \& Gao, 2007), however the greater inhibition of LTA than LPS by polymyxin-B found in this study was most unexpected and therefore possible contamination of LTA was considered of greatest interest.

While equal concentrations of $1 \mu \mathrm{g} / \mathrm{ml}$ of all toxins were used, this is not exactly equivalent in terms of toxin units. Lipopolysaccharide can vary greatly in molecular weight, therefore measurement in endotoxin units (EU) is more correct. Variations in molecular weight also exist for PGN and LTA (Maurer \& Mattingly, 1991; Vollmer, Blanot, \& de Pedro, 2008). As similar concentrations of TNF- $\alpha$ were obtained from positive controls for each toxin, this suggests, as intended, that these (near maximal) concentrations were physiologically equivalent in the whole blood assay.

There is also evidence that polymyxin-B binds directly to ribosomal RNA and thus directly affects transcription of inflammatory cytokines (McCoy et al., 2013). Lipopolysaccharide initiates the inflammatory cascade through TLR-4, while LTA and PGN both initiate inflammation through binding to TLR-2, however the downstream activation of the inflammatory cascade is similar regardless (Schwandner et al., 1999). Despite this, subtle differences in mechanisms of downstream signalling and thus cytokine transcription might 
exist between TLR-4 and TLR-2 activation, which could explain differences in the responses to polymyxin-B in this study (De Nardo, 2015).

Polymyxin-B had a pro-inflammatory effect at higher concentrations in this study seen as an increase in TNF- $\alpha$ production at the two highest concentrations. Polymyxin-B has a dosedependent cytotoxic effect resulting in nephrotoxicity at higher doses that has limited its use in humans and animals (Vattimo et al., 2016). Polymyxin-B promotes TNF- $\alpha$ production by human cultured PBMCs at concentrations greater than $20 \mu \mathrm{g} / \mathrm{ml}$ (Jaber, Sundaram,

Cendoroglo Neto, King, \& Pereira, 1998). Much higher concentrations of polymyxin-B were used in the current study and it is therefore not surprising that pro-inflammatory effects were seen at these concentrations. Another possible reason for the TNF- $\alpha$ increase at the highest concentrations of polymyxin-B is direct cytotoxicity to the bioassay cells. Killing of L929 cells by polymyxin-B rather than TNF- $\alpha$ would reflect as increased TNF- $\alpha$ concentrations. However, the presence of any residual activity of polymyxin-B in the plasma supernatant was not measured; therefore any direct effect of polymyxin-B on bioassay cells cannot be definitively determined. A limitation of this study was that only TNF- $\alpha$ was measured and these effects might have been better characterized by the measurement of other cytokines.

The concentrations of polymyxin-B used in this in vitro study are much higher than those used clinically in horses. At the standard dose of 6000 units/kg (equivalent to approximately $1 \mathrm{mg} / \mathrm{kg}$ ), plasma concentrations of polymyxin-B in horses are $2.98 \pm 0.81 \mu \mathrm{g} / \mathrm{mL}$ (Morresey \& Mackay, 2006), lower than the lowest concentration of $10 \mu \mathrm{g} / \mathrm{ml}$ used in this study. Maximum TNF- $\alpha$ inhibition was not seen until 100-300 $\mu \mathrm{g} / \mathrm{ml}$ in the current study, so this discrepancy is large. This study was designed as a proof of concept study to determine whether polymyxin-B could inhibit TNF- $\alpha$ production caused by bacterial toxins other than LPS, and further work is required to determine whether this effect is still found at lower, clinically relevant concentrations, and more importantly in in vivo and clinical scenarios. The dose described in horses might still be effective in clinical cases of SIRS due to differences and variability in toxin concentrations, however clinical trials for polymyxin-B use in equine SIRS are lacking. Nephrotoxicity caused by polymyxin-B is well described in humans (Dubrovskaya et al., 2015), and subsequently caution is exercised in administering it to horses (Barton et al., 2004). Therefore it would be unlikely that plasma concentrations in horses equivalent to the concentrations of polymyxin-B used in this study could be safely obtained. Likewise, the pre-treatment of whole blood aliquots with polymyxin-B prior to addition of toxins does not replicate a clinical scenario. The study was designed this way in 
order to optimize the response as a proof of concept. While treatment of horses with polymyxin-B after administration of LPS still reduces the inflammatory response in an in vivo LPS challenge model (Barton et al., 2004), this effect is unknown for other bacterial toxins. Further work is required to determine this.

Despite acknowledgement of the above limitations in applying these results to clinical cases of equine SIRS, whether polymyxin-B should be used in equine SIRS at all has to be questioned because of the role the polymyxins play as an antimicrobial category reserved for the treatment of multi-resistant Gram negative bacterial infections in humans (Barriere, 2015; Rapp \& Urban, 2012).

In conclusion polymyxin-B inhibited TNF- $\alpha$ production elicited not only by LPS, but also LTA and PGN. In this model, polymyxin-B was a more potent inhibitor of LTA than LPS or PGN. Further studies are required to determine the mechanism by which polymyxin-B interacts with LTA and PGN.

\section{References}

Barriere, S. L. (2015). Clinical, economic and societal impact of antibiotic resistance. Expert Opinion On Pharmacotherapy, 16(2), 151-153. doi:10.1517/14656566.2015.983077

Barton, M. H., Parviainen, A., \& Norton, N. (2004). Polymyxin B protects horses against induced endotoxaemia in vivo. Equine Veterinary Journal, 36(5), 397-401.

Bauquier, J. R., Tudor, E., \& Bailey, S. R. (2015). Anti-inflammatory effects of four potential anti-endotoxaemic drugs assessed in vitro using equine whole blood assays. Journal Of Veterinary Pharmacology And Therapeutics(3), 290-297.

Bergen, P. J., Landersdorfer, C. B., Zhang, J., Zhao, M., Lee, H. J., Nation, R. L., \& Li, J. (2012). Review: Pharmacokinetics and pharmacodynamics of 'old' polymyxins: what is new? Diagnostic Microbiology \& Infectious Disease, 74, 213-223.

Burrows, G. E. (1971). Escherichia coli endotoxemia in the conscious pony. Am J Vet Res., $32(2), 243-248$.

Burrows, G. E. (1979). Equine Escherichia coli endotoxemia: comparison of intravenous and intraperitoneal endotoxin administration. American Journal Of Veterinary Research, 40(7), 991-998. 
Cudmore, L. A., Muurlink, T., Whittem, T., \& Bailey, S. R. (2013). Effects of oral clenbuterol on the clinical and inflammatory response to endotoxaemia in the horse. Research in Veterinary Science(3), 682-686.

De Nardo, D. (2015). Review Article: Toll-like receptors: Activation, signalling and transcriptional modulation. Cytokine, 74, 181-189.

Declue, A. E., Johnson, P. J., Day, J. L., Amorim, J. R., \& Honaker, A. R. (2012). Pathogen associated molecular pattern motifs from Gram-positive and Gram-negative bacteria induce different inflammatory mediator profiles in equine blood. The Veterinary Journal, 192(3) 455-460.

Dubrovskaya, Y., Prasad, N., Lee, Y., Esaian, D., Figueroa, D. A., \& Tam, V. H. (2015). Risk factors for nephrotoxicity onset associated with polymyxin B therapy. The Journal Of Antimicrobial Chemotherapy, 70(6), 1903-1907.

Duncan, S. G., Meyers, K. M., Reed, S. M., \& Grant, B. (1985). Alterations in coagulation and hemograms of horses given endotoxins for 24 hours via hepatic portal infusions. American Journal Of Veterinary Research, 46(6), 1287-1293.

Ellouz, F., Adam, A., Ciorbaru, R., \& Lederer, E. (1974). Minimal structural requirements for adjuvant activity of bacterial peptidoglycan derivatives. Biochemical and Biophysical Research Communications, 59, 1317-1325.

Fessler, J. F., Bottoms, G. D., Coppoc, G. L., Gimarc, S., Latshaw, H. S., \& Noble, J. K. (1989). Plasma endotoxin concentrations in experimental and clinical equine subjects. Equine Veterinary Journal. Supplement(7), 24-28.

Forbes, G., Church, S., Savage, C. J., \& Bailey, S. R. (2012). Effects of hyperimmune equine plasma on clinical and cellular responses in a low-dose endotoxaemia model in horses. Research in Veterinary Science, 92(1), 40-44.

Gao, J. J., Xue, Q., Zuvanich, E. G., Haghi, K. R., \& Morrison, D. C. (2001). Commercial preparations of lipoteichoic acid contain endotoxin that contributes to activation of mouse macrophages in vitro. Infection And Immunity, 69(2), 751-757.

Hay, H., \& Cohen, J. (1989). Studies on the specificity of the L929 cell bioassay for the measurement of tumour necrosis factor. J Clin Lab Immunol., 29(3), 151-155.

Jaber, B. L., Barrett, T. W., Cendoroglo Neto, M., Sundaram, S., King, A. J., \& Pereira, B. J. (1998). Removal of cytokine inducing substances by polymyxin-B immobilized polystyrene-derivative fibers during in vitro hemoperfusion of $10 \%$ human plasma containing Staphylococcus aureus challenge. ASAIO Journal (American Society For Artificial Internal Organs: 1992), 44(1), 48-53. 
Jaber, B. L., Sundaram, S., Cendoroglo Neto, M., King, A. J., \& Pereira, B. J. (1998). Polymyxin-B stimulates tumor necrosis factor-alpha production by human peripheral blood mononuclear cells. The International Journal Of Artificial Organs, 21(5), 269273.

Johns, I., Tennent-Brown, B., Schaer, B. D., Southwood, L., Boston, R., \& Wilkins, P. (2009). Blood culture status in mature horses with diarrhoea: A possible association with survival. Equine Veterinary Journal, 41(2), 160-164.

Kusumoto, S., Fukase, K., \& Shiba, T. (2010). Key structures of bacterial peptidoglycan and lipopolysaccharide triggering the innate immune system of higher animals: Chemical synthesis and functional studies. Proceedings of the Japan Academy. Series B, Physical and Biological Sciences, 86(4), 322-337.

Leise, B. S., Yin, C., Pettigrew, A., \& Belknap, J. K. (2010). Proinflammatory cytokine responses of cultured equine keratinocytes to bacterial pathogen-associated molecular pattern motifs. Equine Veterinary Journal, 42(4), 294-303.

Lewis, D. H., Chan, D. L., Pinheiro, D., Armitage-Chan, E., \& Garden, O. A. (2012). The Immunopathology of Sepsis: Pathogen Recognition, Systemic Inflammation, the Compensatory Anti-Inflammatory Response, and Regulatory T Cells. Journal of Veterinary Internal Medicine, 26(3), 457-482.

Maurer, J. J., \& Mattingly, S. J. (1991). Molecular analysis of lipoteichoic acid from Streptococcus agalactiae. Journal Of Bacteriology, 173(2), 487-494.

McCoy, L. S., Roberts, K. D., Nation, R. L., Thompson, P. E., Velkov, T., Li, J., \& Tor, Y. (2013). Polymyxins and analogues bind to ribosomal RNA and interfere with eukaryotic translation in vitro. Chembiochem: A European Journal Of Chemical Biology, 14(16), 2083-2086.

Moore, J. N., \& Vandenplas, M. L. (2014). Is it the Systemic Inflammatory Response Syndrome or Endotoxemia in Horses with Colic? Veterinary Clinics of North America: Equine Practice, 30, 337-351.

Morresey, P. R., \& Mackay, R. J. (2006). Endotoxin-neutralizing activity of polymyxin B in blood after IV administration in horses. American Journal Of Veterinary Research, 67(4), 642-647.

Morrison, D. C., \& Jacobs, D. M. (1976). Binding of polymyxin B to the lipid A portion of bacterial lipopolysaccharides. Immunochemistry., 13(10), 813-818. 
Parviainen, A. K., Barton, M. H., \& Norton, N. N. (2001). Evaluation of polymyxin B in an ex vivo model of endotoxemia in horses. American Journal Of Veterinary Research, 62(1), 72-76.

Peek, S. F., Borah, S., Semrad, S., McGuirk, S., Slack, J. A., Patton, E., . . Darien, B. J. (2004). Plasma endotoxin concentration in horses: a methods study. Veterinary Clinical Pathology / American Society For Veterinary Clinical Pathology, 33(1), 2931.

Peiró, J. R., Barnabé, P. A., Cadioli, F. A., Cunha, F. Q., Lima, V. M. F., Mendonça, V. H., . . . Valadão, C. A. A. (2010). Effects of lidocaine infusion during experimental endotoxemia in horses. Journal Of Veterinary Internal Medicine / American College Of Veterinary Internal Medicine, 24(4), 940-948.

Percy, M. G., \& Grundling, A. (2014). Lipoteichoic acid synthesis and function in grampositive bacteria (Vol. 68, pp. 81-100): Section of Microbiology and MRC Centre for Molecular Bacteriology and Infection, Imperial College London, London, SW7 2AZ UK

Rapp, R. P., \& Urban, C. (2012). Klebsiella pneumoniae carbapenemases in Enterobacteriaceae: history, evolution, and microbiology concerns. Pharmacotherapy, 32(5), 399-407.

Russell, C. M., Axon, J. E., Blishen, A., \& Begg, A. P. (2008). Blood culture isolates and antimicrobial sensitivities from 427 critically ill neonatal foals. Australian Veterinary Journal, 86(7), 266-271.

Schwandner, R., Dziarski, R., Wesche, H., Rothe, M., \& Kirschning, C. J. (1999). Peptidoglycan- and lipoteichoic acid-induced cell activation is mediated by toll-like receptor 2. The Journal Of Biological Chemistry, 274(25), 17406-17409.

Scott, M. G., Gold, M. R., \& Hancock, R. E. (1999). Interaction of cationic peptides with lipoteichoic acid and Gram positive bacteria. Infection And Immunity, 67(12), 64456453.

Suda, Y., Tochio, H., Kawano, K., Takada, H., Yoshida, T., Kotani, S., \& Kusumoto, S. (1995). Cytokine-inducing glycolipids in the lipoteichoic acid fraction from Enterococcus hirae ATCC 9790. FEMS Immunology And Medical Microbiology, 12(2), 97-112.

Tadros, E. M., \& Frank, N. (2012). Effects of continuous or intermittent lipopolysaccharide administration for 48 hours on the systemic inflammatory response in horses. American Journal Of Veterinary Research, 73(9), 1394-1402. 
Theelen, M. J. P., Wilson, W. D., Edman, J. M., Magdesian, K. G., \& Kass, P. H. (2014).

Temporal trends in prevalence of bacteria isolated from foals with sepsis: 1979-2010. Equine Veterinary Journal 46(2) 169-173.

Tsan, M.-F., \& Gao, B. (2007). Pathogen-associated molecular pattern contamination as putative endogenous ligands of Toll-like receptors. Journal of Endotoxin Research, 13(1), 6-14.

Tsutsui, O., Kokeguchi, S., Matsumura, T., \& Kato, K. (1991). Relationship of the chemical structure and immunobiological activities of lipoteichoic acid from Streptococcus faecalis (Enterococcus hirae) ATCC 9790. FEMS Microbiology Immunology, 3(4), 211-218.

Vattimo, M.d. F. F., Watanabe, M., da Fonseca, C. D., Neiva, L. B. d. M., Pessoa, E. A., \& Borges, F. T. (2016). Polymyxin B Nephrotoxicity: From Organ to Cell Damage. PLoS ONE, 11(8), 1-17.

Vollmer, W., Blanot, D., \& de Pedro, M. A. (2008). Peptidoglycan structure and architecture. FEMS microbiology reviews 32(2) 149-168.

Wang, J. E., Dahle, M. K., McDonald, M., Foster, S. J., Aasen, A. O., \& Thiemermann, C. (2003). Peptidoglycan and lipoteichoic acid in gram-positive bacterial sepsis: receptors, signal transduction, biological effects, and synergism. Shock, 20(5), 402414.

Werners, A. H., Bull, S., \& Fink-Gremmels, J. (2005). Endotoxaemia: a review with implications for the horse. Equine Veterinary Journal, 37(4), 371-383.

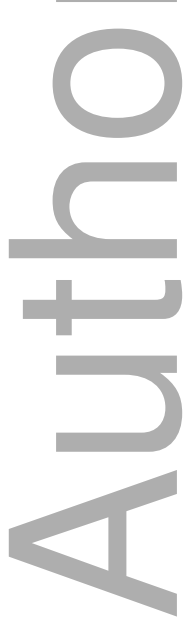



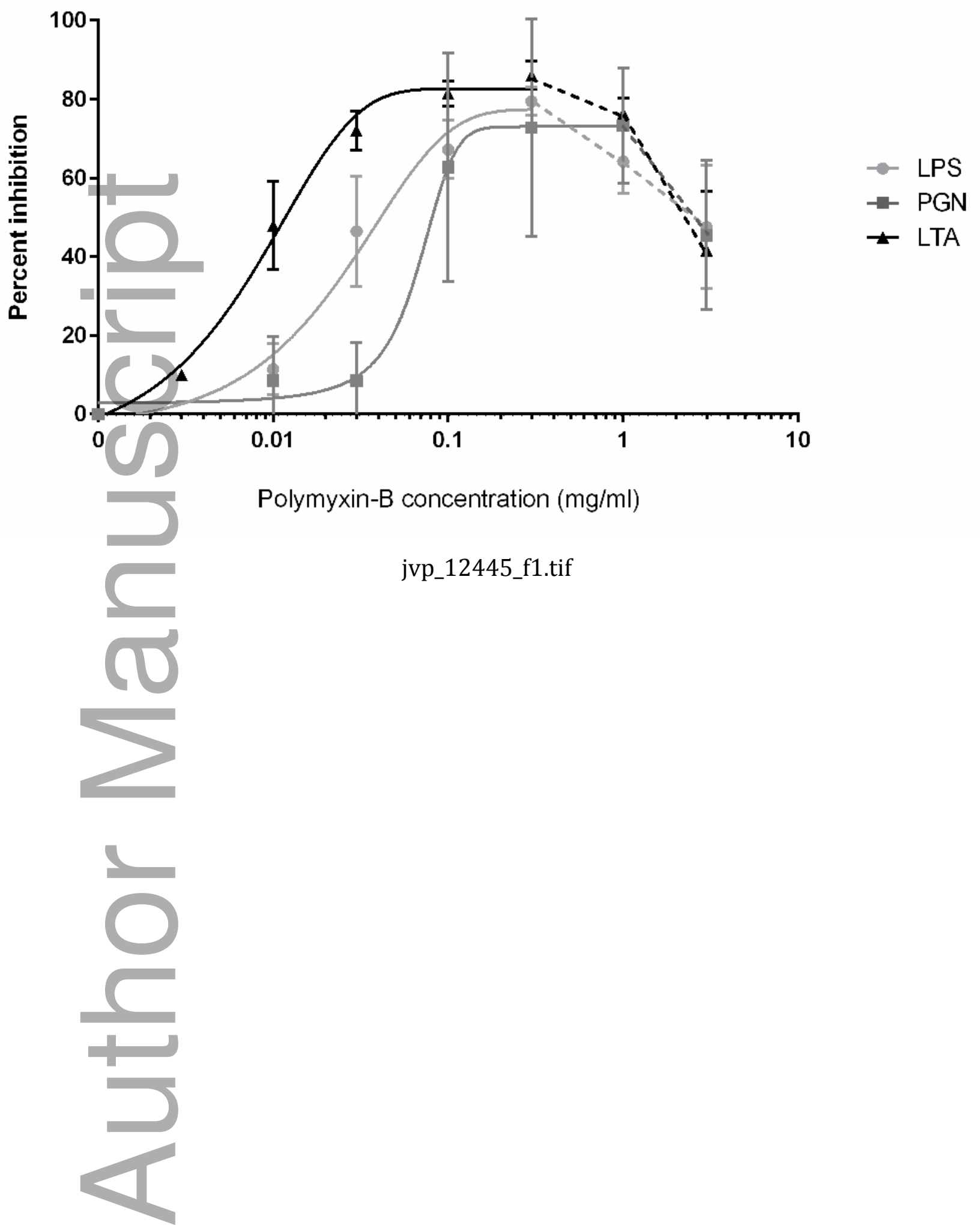

This article is protected by copyright. All rights reserved 


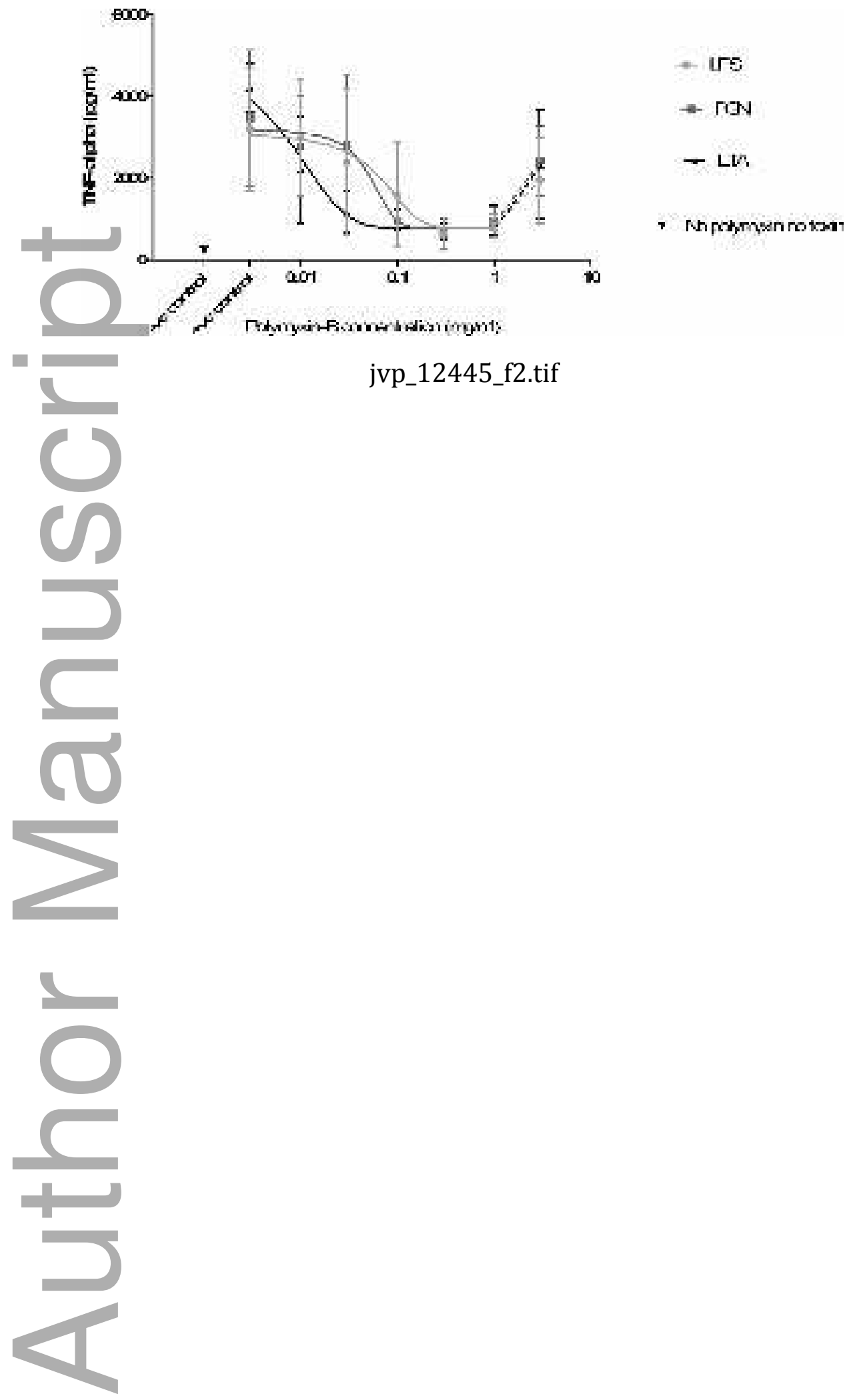

This article is protected by copyright. All rights reserved 


\section{University Library}

\section{- M M N E R VA A gateway to Melbourne's research publications}

Minerva Access is the Institutional Repository of The University of Melbourne

Author/s:

Bauquier, JR;Tennent-Brown, BS;Tudor, E;Bailey, SR

Title:

Effects of polymyxin-B on TNF-alpha production in equine whole blood stimulated with three different bacterial toxins

Date:

2018-02-01

Citation:

Bauquier, J. R., Tennent-Brown, B. S., Tudor, E. \& Bailey, S. R. (2018). Effects of polymyxin$B$ on TNF-alpha production in equine whole blood stimulated with three different bacterial toxins. JOURNAL OF VETERINARY PHARMACOLOGY AND THERAPEUTICS, 41 (1), pp.E35-E39. https://doi.org/10.1111/jvp.12445.

Persistent Link:

http://hdl.handle.net/11343/293321 